\title{
The Role of Phonetics and Prosody during a Second Language Learning Plan
}

\author{
By Maria Rosaria D'Acierno Canonici
}

\begin{abstract}
New technologies have changed the methodology applied to the teaching of foreign languages. Moreover, teachers do not use them sufficiently. The oral language should gain more ground because communication uses speech more than writing. Each language has its phonetic, phonological and prosodic system. These features become important during a foreign language learning process, since the learner tends to assimilate the foreign sound to the sounds of his/her mother tongue because 1) his/her ear is not able to distinguish them, and 2) the brain couples the sound with the written sign. By following a traditional methodology, students achieve an adequate level in constructing correct sentences, but their oral performance remains poor. New technologies help students to practice the new sounds more precisely, thus, provoking the muscle of the phonetic apparatus to become so stretched to be able to produce them easily. Talking in a new language is the equivalent of making a physical exercise; it is a question not only of new commands received by the brain, but also of a flexible vocal tract. It is a physical, psychological and mental process, which, considering Italian and English, becomes even more difficult, because the two alphabets have more or less the same written signs ( $a, b, c, d$, $t$, etc.). Rather, if we consider an Italian student of Arabic the problems are different for two reasons: 1) the letters, having different shape, avoid overlapping, so that the student 2) has only to develop the muscles for the emphatic and

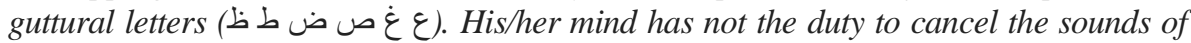
the mother tongue and to substitute them with a new pronunciation. In this study, my challenge is to give much more emphasis to phonetics, phonology, stress and intonation, so to facilitate interaction during a speech act using real and not a limited classroom language. For these reasons, I planned a specific course in pronunciation, helped by spectrographs and laryngographs, for a separate group of students with the purpose to stress phonetics and phonology more than grammar. The results obtained after one year, at last, gave voice to my suppositions.
\end{abstract}

Keywords: methodology, foreign languages, phonetics, phonology, prosody

\section{Introduction}

"There are many different sorts of voicing that we can produce - think of the differences in the quality of your voice between singing, shouting and speaking quietly, or think of the different voices you might use reading a story to young children in which you have to read out what is said by characters such as giants, fairies, mice or ducks; many of the differences are made with the larynx. We can make changes in the vocal cords themselves - they can be made longer or shorter, more tense or more relaxed or be more or less strongly pressed together. The pressure of the air below the vocal cords can also be varied." (Roach 1983, p. 27)

After reading this quotation it is clear that this essay is about the importance of the voice, and of all the nuances that give colour to our discourse during a speech act. Moreover, this paper wants to emphasize the crucial role of the voice

*Associate Professor, University of Naples Parthenope, Italy. 
during a conversation between a mother tongue and a foreign speaker, especially if this conversation is a working conversation for professional aims. For this reason, my research covers the field of foreign language learning and teaching in order to improve speech as well as oral comprehension between two or more speakers.

The learners I refer to are the Italian university students of the Department of Viticulture and Oenology learning English. These students are offered only one course in English for special purposes throughout their university career. Following this methodology, the accent is on specific vocabulary and idiomatic expressions related to their fields of study. Unfortunately, the basic course does not include any reference to phonetics and intonation, so that, at the end of the academic year, a split between the oral and the written communication has been created. They have achieved a good level in the written skill since they have acquired a large vocabulary connected to the phases of vinification, but they are not able to communicate through speech because they cannot either understand or answer any question. In other words, there is no balance between the written and the oral system of the English language they have been studying for one year. The situation of this department is common to that of the other departments where English is learned for special purposes (Economics, Physical Education, Engineering, etc.). Based on my previous teaching experience in a university specialized in foreign languages, I decided to take advantage of the Laboratory of Experimental Phonetics ${ }^{1}$ to train a small group of students in order to offer them, in combination with the general grammar course, a session in which phonetics, phonology and prosody would gain an important role.

In brief, the languages involved are Italian (the students' mother-tongue), and English (their foreign language). I achieved this conclusion, because I think that the majority of the learners have great problems when they attend international meetings in which English is requested. After all, the language they have studied reflects only one aspect of communication; that is to say, the one belonging to the formal written communication, totally forgetting the oral skill.

A cross-linguistic analysis between Italian and English, focusing mainly on the acquisition of speech features, has guided the present experimental plan. Thus, stimulated by past experiences applying such an analysis (comparison between the two phonetic-phonological systems), I forged my new foreign language teaching class (Py 1996, Read 1978). Adding cultural details within the lessons and comparing the ways of life of the two populations will increase the semantic evaluation of discourse. The comparison between the native and the foreign language and culture, as well as the knowledge of the physiological organs involved during speech will greatly help the acquisition of communicative competence. Moreover, stressing the role of pronunciation, and focusing on intonation patterns, will avoid misunderstanding and distortion of discourse. We know that an adult learner cannot easily hear and then pronounce correctly the sounds of a new language immediately, even though he has no speech impediment and he suffers no hearing defect. Despite this, s/he is called 'stutterer' and 'deaf,'

\footnotetext{
1،... il lavoro della fonetica sperimentale, sfruttando i progressi della tecnologia, dovrebbe consistere nel mettere in evidenza, nell'oggettivare le caratteristiche fisiche, acustiche e, fisiologiche di queste voci." (De Dominicis 2002, p. 73), cf. Wells (1982).
} 
because s/he does not recognize even very familiar words. In a non-phonetic language as English is, also rich in homophones (e.g., affect-effect; flow-floe; flower-flour; heart-hart; higher-hire, etc.), there is no match between written and oral words, so the task becomes really difficult. The students' ear has to be trained to perceive real speech, that is why they cannot understand sequences of utterances in which words blend. In English a consonant at the end of a word blends with the vowel that begins the next word (We might find some red berries here becomes in "unconventional spelling" speech, as Smith (1975, p. 351) calls this phenomenon, Wee mite fined sum read buries here). As a consequence of the liaison process, also timing speech is compromised, so the gap enlarges. On the contrary, linguistic competence means to achieve the same level of knowledge in each skill, either phonological, semantical, syntactical, so that, students can perform both illocutionary (oral) and propositional acts (written). Because our students need speech more than writing, they should be trained to perform utterances which affect the audience/hearer, since they require or ask for an answer, or some feedbacks which stimulate the whole of discourse. Speech informs, convinces, requests, in other words, influences the listener's feelings, thoughts and actions; relevant features, especially during a business transaction. Of course, perlocutionary, illocutionary/locutionary acts, which are composed of a phonetic and a phatic act, might also, by using a particular sound inflection or a particular stress on some words, mean something beyond the literal meaning of the sentence. That is the case when the voice adds insinuations, irony, metaphors etc.

Searle (1997, p. 30) gives us this example: Can you reach the salt? Both meaning either the literal sense of the question or a gentle request.

"We have ample evidence that when learning a foreign language, we tend to transfer our entire native language system in the process. We tend to transfer to that language our phonemes and their variants, our stress and rhythm patterns, our transitions, our intonation patterns and their interaction with other phonemes.... The speaker of one language listening to another does not actually hear the foreign language sound units - phonemes. He hears his own. Phonemic differences in the foreign language will be consistently missed by him if there is no similar phonemic difference in his native language." (Lado 1957, p. 11)

In brief, when a phoneme of the foreign language does not exist in the native language, the student's deaf ear substitutes it with a similar native phoneme. A methodology stressing the contrast between the sounds of the two languages will help the ear and the brain to recognize the differences, so that the muscles of the vocal tract receive the correct stimuli and, after a series of exercises, are ready to utter the correct sounds. For example, the student has to go through various steps (theoretically and practical) before being able to perceive the difference between the dental-voiceless-fricative $t \theta$ in think in contrast to the dental-voiced-fricative $t$ $ð$ in then, and $t$ in ten, in which it is a plosive (Lado 1957, p. 24).

Thus, being the focus on the oral language, pronunciation and intonation should cover the most relevant role during the learning/teaching schedule through sessions stressing the importance of phonetics, phonology and prosody. Nowadays, technology helps this approach greatly, and experimental phonetics seems to be a 
valuable aid, because it guides both ear and eyes by providing images that point out every nuance of the voice recorded even revealing timing speech issues, which in English are important data. By using a spectrograph, teachers help students to identify visually, the stress, the pitch, the time, the intonation of their utterances. The voiced sound is analysed in detail, so that students can compare their voice, also printed on a diagram, with that of mother tongue speakers. By following this procedure, we teachers help students to recognize the many differences between the two languages, which a non-native's ear is not able to perceive instantly during a speech unit.

Another more complex machine is the laryngograph monitoring the vocalfold activity during ordinary speech. The laryngograph, used principally to correct linguistic problems, especially related to deaf population, would be a valid instrument for increasing the foreign language learning methodology. It will help the student's deaf ear ${ }^{2}$ to visualize the movements of the larynx when pronouncing foreign words. It will be extremely important, since it corrects the inappropriate use of voiced or voiceless segments in an utterance, as well as the duration of vowels, nasals, laterals preceding voiced or voiceless consonants and so on:

"Electronic aids will not diminish the role of teachers or speech therapists, however. On the contrary, their effectiveness will be increased, but greater demands will be made of them as the effective use of speech processing devices in teaching and therapy depends on the teachers having a thorough knowledge of the phonetic bases of the linguistic structures of their language. ... In normal speech, timing and intonation play a vital role. ... Intonation is not a superficial attribute of speech; normally it is the basis on which all else is built. Without sufficient auditory feedback, intonation and rhythm, like other speech skills, are abnormal." (Abberton and Fourcin 1975, p. 157)

The methodology applied to the learning of a foreign language should take into great account the specific studies concerning the development of the language in children and deaf people, for the simple reason that the foreign student has to go across the same steps followed by the child during his development. S/He has to learn a new language, s/he has to adapt her/his deaf ear to new sounds, new pitches, new intonation; s/he has to stretch his vocal muscles in order to achieve a new flexibility suitable for new positions, while the brain has to store the new information and send it to the various organs suitable for speech.

Of course, a methodology focusing on phonetics needs the collaboration of an expert and motivated team, where all members aim at promoting such learning schedule. While following this scheme, motivation is also encouraged and stimulated.

In sum, this study endeavours to achieve an adequate proficiency in the oral production and comprehension of the foreign language, without negating the study of grammar, rather, accompanying it during the whole learning process. Thus, I want to highlight all the nuances of the oral language through a much careful and

${ }^{2}$ Deaf-ear not because of physiological problems, but only because foreign students are not able to perceive the sound nuances of the foreign tongue. 
attentive consideration of the phonetic system of the tongue studied; a phonetic system, at first faced theoretically, and then, experienced with the help of technological aids (spectrographs and laryngographs). This happens because language is a complex arrangement made of oral and written communication, where the oral speech also provides rules, often forgotten or underestimated, so depriving language of a vital side. A low-level spoken language frustrates the speaker who feels unable to speak because his/her ear is unqualified to hear; moreover, it creates a big gap between the written and the spoken discourse. In order to avoid all these problems, our plan stimulates the teaching of foreign languages by starting with a full and long course in phonetics and phonology even anticipating the formal teaching of the written system. The languages used during the experiment are Italian (mother tongue) and English (foreign language). Arabic has been introduced only as an example to highlight the contrast existing between this Semitic language and the Indo-European languages, and also because its acquisition, which I want to stimulate, will surely facilitate the learning of other foreign languages, since Arabic is so rich in sounds that trains the muscles of the vocal area in order to cover all the possible nuances related to its alphabetical letters.

\section{Planning English as a Global Language: The Brain and the Vocal Tract}

In our global world, we all know that English is the lingua franca mostly used for commerce and business, so that this language, spread everywhere, should have achieved an adequate and acceptable proficiency among foreign speakers. Unfortunately, this is not the case, since the majority of people show very low levels and try to rely either on body movements, or any other compromise in order to fulfil a satisfactory business transaction or to be understood during a cultural seminar or a conference when the speaker asks for help to video images, handouts or slides. Poor English level is caused, in my opinion, by two reasons, which are difficult to understand in our multicultural/multilingual world, so highly civilized, and with so many foreign languages and cultures around us. I try to explain this phenomenon from my point of view.

1) Learning a foreign language, should not be driven only by better working opportunities so that, once one has learned a few rules within a specific vocabulary and phrases, the goal seems to have been achieved. Rather, approaching a foreign language is a matter of cultural, mental and behavioural acquisition first of all. Fortunately, we can remedy this low approach, because as Michael StuddertKennedy said many years ago (1983) in the Foreword of John L. Locke's book Phonological Acquisition and Changes: "Language now becomes a mental organ or, if we prefer computer metaphors, a module" (Locke 1983, p. ix). Under these premises, by considering language an organ, we can study it from its physiological, anatomical and mental development in order to understand how inborn faculties shape the growth of language in general, and speech in particular, according to the impulses derived from both environment and context. This process, helped also by that of imitation, the most relevant spring either for a child or for an adult learning 
a foreign language, works very well. Studdert-Kennedy adds, under the influence of the epigenetic process, that this process permits through "an accumulation of adaptive changes" to acquire the accent, lexicon, and syntax of the language one is exposed to. The child's initial phonetic proclivities modify during life according to the particular environment, and survive in the adult, eventually to conform to the learning of new languages. This procedure finds an example when we examine babbling, which mainly seems to be common to all children despite their linguistic environment. This phenomenon shows that the muscles of the vocal tract have to be strengthened first of all through canonical babbling ${ }^{3}$. Only later, when the child's articulatory organs and also his mind have achieved a certain maturity, the process of adaptation to the linguistic inputs around the child will start.

Roman Jacobson was one of the few phonological theorists, who gave much attention to the data coming from child's speech development. He distinguishes two discontinuous periods of phonological growth when analysing children's speech: 1) the pre-language babbling, in which the sounds of the child's vocalization do not follow any particular order of development, and are not related to the later productions, and 2) the acquisition of the language proper, that is relatively universal, during which the child acquires the sounds of the language around him/her. In so doing, Jacobson highlights the difference between the mere production and the systematic use of the sound (cf. Jacobson and Halle 1956).

For the adult learning a foreign language, it might be the same; certain articulatory muscles have never been used, so that they have to be stretched and stimulated, once the mind and the ear recognize the different sound required by the phonemes belonging to the foreign language. The motivation, driving that learning, should involve our mood up to the point that we feel part of the community we are learning their mother tongue. This atmosphere is absent in the one whose aim, when learning a foreign language, follows only practical working purposes. As a consequence, the learner wants to achieve the acquisition of the foreign language (English) as soon as possible. Rather, we all know that patience is the first virtue guiding foreign language learning. It takes time because our brain has to adapt to

\footnotetext{
${ }^{3}$ Research has shown that $95 \%$ of infants babbled vocalizations involve the 12 speech sounds that are most common across the world's languages: $\mathrm{m}, \mathrm{d}, \mathrm{j}, \mathrm{p}, \mathrm{h}, \mathrm{b}, \mathrm{w}, \mathrm{t}, \mathrm{n}, \mathrm{k}, \mathrm{g}$, and $\mathrm{y}$. The vocalizations babbled by all infants are strikingly similar across the world, regardless of the infants' native language. It is common for infants to produce speech sounds that are not among the speech sounds of their native language. For example, infants reared in English-speaking environments may produce non-English speech sounds, such as the click sounds that occur in certain African languages. Likewise, infants reared in Japanese-speaking environments may produce speech sounds not occurring in Japanese, such as [r]. As infants mature, more of the speech sounds produced are those speech sounds heard in the environment in the language or languages of the home, and fewer of them are speech sounds from other languages. This phenomenon has been referred to as babbling drift (cf. Hoff 2001). Of course, there are two opposing school about the theories concerning babbling: 1) one following R. Jacobson's prelinguistic conception attesting "an astonishing quantity and diversity of sound productions ... never found within a single language or even a group of languages," the other 2) adopting R. Brown's babbling drift conception which poses his theory on "the fact that (babbling) drifts in the direction of the speech the infant hears." Thus, babbling is influenced by the language around the child. In conclusion cross-linguistic babbling has produced a large literature even attesting opposed realities (Jacobson 1968, p. 21, Brown 1958, Weir 1966). Cf. Ashby and Maidment (2005).
} 
the new stimuli that regulate the perception of the reality around us. Our ear has to be able to recognize new sounds and our mind and our eyes have to associate the new sounds to the letter of the new alphabet. If the foreign language belongs to the same linguistic family (e.g., English and Italian) might be much confusing, because the learner tends to associate the two signs during the vocal uttering. Rather if the foreign language belongs to another family tree (e.g., Arabic and English), the student does not confuse the two written signs but still pair their sounds if the teacher does not carefully describe the two sounds from the phonetic point of view, also showing the position of the mouth, the lips and the tongue; thus, focusing on the whole of the vocal cavity mechanism.

In brief, our lungs, our lips, and our glottal muscles have to be prepared to take different positions when speaking two or more languages (Figure 1). As we have seen before, this is possible because even the adult learner has not lost the capacity to adapt his/her organs to the stimuli coming from other languages. Considering the oral aspect of speech production, also hearing, repetition, practice, memorization, etc. become main features, when we want to achieve an adequate performance in a new language. Training the ear, as well as providing a formal knowledge of how sounds are performed, go hand in hand during a methodology whose focus is on oral production.

Figure 1. The Vocal Tract

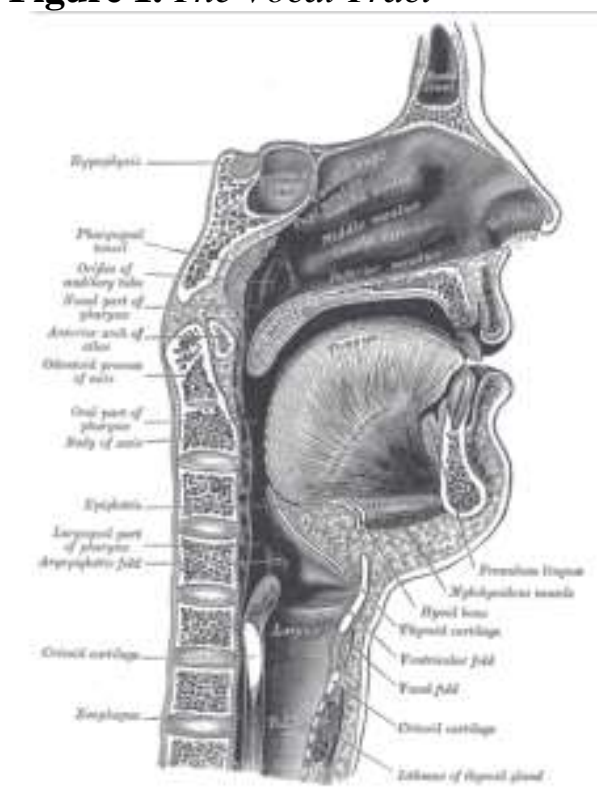

Source: Wikipedia.

2) The other problem when planning a foreign language course is related to the approach suggested. Emphasis is generally given to the explanation of grammatical rules which prepare the formal use of the language, while less weight is given to direct interaction during formal and informal speech. From my perspective, any foreign language plan should start with a phonetic course examining the pronunciation of the letters of the alphabet, and then, proceeding with the single sounds in different positions within the words, up to utter full 
sentences and paragraphs. This course should support the one about grammar for the whole learning scheme since pronunciation is the most difficult skill to be acquired. Being able to understand someone else's voice takes time because the learner has to get used to the speaker's vocal tonality first, then, to the sounds of the foreign language, once he is able to dissociate them from the ones belonging to his mother tongue. When teaching English pronunciation, we have to face two well distinct problems, one not excluding the other: 1) the first is related to phonetics (perception of the sound) and 2) the other has to consider the rules of pronunciation. In English, for example, there are many rules: e.g., silent L after $a$, $o, u$; e.g., walk - B silent after $m$ e.g., bomb - voiced and unvoiced consonants e.g., pledge pledz, etc. These rules are often neglected and delegated to the practical use of the language. But practice comes after conscious apprenticeship leading to conscious knowledge, otherwise the ear remains always deaf. Once the student has internalized the rule through a series of exercises in which a phoneme is evidenced, he will be able to memorize all the alternatives related to that sound by practising it through repetition. Because most of the students are called 'tonedeaf,' since they identify any sound of the foreign language in terms of their mother tongue, especially when helped by the fact that the two languages use the same signs for the alphabetical letters (b, c, d, etc), the teacher has to insist on phonetics and phonology. Of course, this phenomenon happens also when the alphabet uses different symbols. It is extremely difficult to distinguish and to pronounce the long and the short vowels, which determine also the accent of the word, as well as the emphatic sounds of the Arabic letters ض ص ط ط (Z, T, S, D) or the guttural sounds related to $\dot{\varepsilon}$ from similar sounds in Indo-European languages. Besides, from the phonological point of view, the deaf ear might impede to identify the pitches and the tones distinguishing one language from another, even though Indo-European languages share more or less the same intonation patterns, especially considering simple interrogatives. Declarative utterances at the end share the same relatively high to relatively low pitch in most Western languages. Rather the difference, which becomes important to focus on with students of English, is tested in both simple questions (e.g., Are you coming?) and questions beginning with an interrogative word (Wh questions: e.g., Where are you going?) that end with a falling pitch. (Italian questions end with a high tone while English wh questions tend to end with a low tone (How old are you? Where do you come from?). This typical English intonation comes from the relationship between intonation and grammar since the grammatical structure of the sentence influences the pitch contours of an utterance. 'Wh'questions have a falling tone (Figure 2).

Figure 2. Intonation

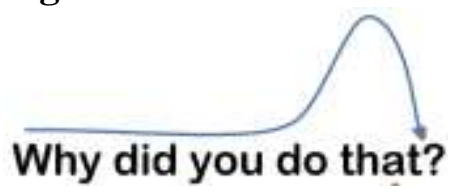

In English, the order of elements in pattern questions is fixed, so that each sentence unit is determined by its syntactic function. In this case, it seems that 
even intonation follows a kind of "grammatical" rule. These syntactical rules in other languages are not so determined when constructing a sentence or an utterance, and they can be of three types: 1) functional, 2) concomitant and 3) weak. In this case, the intonation is much more influenced by the speaker's attitude and by the context. Of course, the context has always a strong weight in determining the sense of the words beyond their referential lexical meaning. Any discourse, either spoken or written cannot be treated in isolation, with its context stripped away, because in any case, its relevance evaporates and as Richard Gunter says: "without context there is no relevance. ... Context may have an important bearing even upon the lexical meaning of an utterance" (Gunter 1972, p. 194). After acquiring the most essential 'rules' about intonation, the time the student has achieved a high proficiency, he/she may alter the formal intonation pattern according to his/her attitudes and reactions. This alteration will no longer come from mother-tongue suggestions, but rather, from a conscious examination of the content as well of the context. Any interruptions, changes of pitches, breaks, in other words, any pattern variations from the standard pronunciation will not reveal poor language production, rather a conscious alternative used in order to insist and to focus on some phonemes or words which serve to give them a particular emphasis within the discourse. This is called "fluctuation in pitch," a device that occurs in all languages when the speaker reacts to a situation.

"Fluctuation in pitch occurs in the sentences of all languages. No language uses a pure monotone. Once a person trains himself to listen for pitch in speech he notices considerable fluctuation even in the voices of persons reputed to be monotones. ... the changes of pitch which occur within a sentence are not haphazard variation. The patterns of variation, the rules of change, are highly organized. ... In each language, however, the use of pitch fluctuation tends to become semi-standardized, or formalized, so that all speakers of the language use basic pitch sequences in similar ways under similar circumstances. These abstracted characteristic sentence melodies may be called intonation contours. ... In English, many intonation contours are explicit in meaning. Whenever a certain sequence of relative pitches is heard, one concludes that the speaker means certain things over and above the specific meanings of the words themselves. A change of pitch contour will change the meaning of the sentence." ${ }^{4}$ (Pike 1972, p. 53)

Emotive intonation does not point only on one word or one utterance, rather it might cover other words or phrases, too. It might even be justified by the syntactical structure of the whole speech act. To achieve this level, when speaking in a foreign language, means to have deeply internalized the mind of the people speaking that language. This process takes a long time and many hours of imitation exercises. Imitation means to try to modulate one's own voice on the sound of the foreign language, on the many pitches typical, in our case, of the English language,

\footnotetext{
4"La voce non è solo lo strumento di realizzazione del piano del significante, ed in quanto tale, in un certo senso ancella del significato, ma è anche strumento, per così dire, autoreferenziale, portatore e generatore di sensi in sé, in una dimensione olistica, iconica, in cui significante e significato tendono a coincidere: ..." (De Dominicis 2002, p. 52). Cf. Hughes et al. (2005), Ladefoged and Johnson (2011), Locke et al. (1956), Schneider et al. (2004).
} 
so many that "the American thinks the Britisher is 'singing' rather than speaking normally" (Hall 1972, p. 283).

“... one can detect the rhythm of ... a piece of music. ... It has often been claimed that English speech is rhythmical ... The theory that English has stress-timed rhythm implies that stressed syllables will tend to occur at relatively regular intervals whether they are separated by unstressed syllables or not; ... Many foreign learners of English are made to practise speaking English with a regular rhythm, often with the teacher beating time or clapping hands on the stressed syllables. It must be pointed out, however, that the evidence for the existence of stress-timed rhythm is not strong.", (Roach 1983, pp. 102-103)

To be able to control one's own voice is not an easy matter, even for mothertongue speakers. Intonation and prosody, often helped by paralinguistic features, reveal inner thoughts and reactions, most of the time not sufficiently masked by the structure of the sentences. Talking with a clear, well-modulated, pleasant voice that attracts and captures the listener's interest is a virtue that requires practice and attention.

Since any people develop, either personal intonation (contours showing physiological/psychological states like anger or happiness or reactions to a certain atmosphere) or formal pitch sequences typical of the mother tongue spoken, the foreign speaker needs to learn these features, otherwise, his/her communication will be compromised, and s/he will soon be labelled as a foreigner with a bad accent and a low knowledge of the language. A wrong intonation contour, always considering the context, besides altering the intrinsic lexical meaning of the utterance, might also confuse the listener who is not able to pair the speaker's kinesic features (facial expression, body movements, distance, etc.) with paralanguage signals (pitch, volume, modulation, tone, etc.). If, for example, an Italian student of English utters an interrogative (e.g., Where are you going?) following only the native rising intonation contour, s/he might be misinterpreted as adding a sense of reproach to a simple question. Such a shift of meaning is only determined by the fact that he interprets everything in terms of his own language. The student should become aware of the differences as well as the similarities between the mother tongue and the foreign language; similarities we can find more easily from the intonation side if the learner is Italian and s/he is learning Arabic. Rather, the differences, as above stressed, are related to the phonetic production of emphatic, guttural and vocal stops letters.

Generally speaking, students are not able to distinguish and even to perceive an up from down tone. This phenomenon regulates the listening of our mother tongue, too. When mother tongue speakers listen to somebody, very rarely perceive differences related to pitches or tones, and when they perceive them, these do not disturb listening comprehension, because, as O'Conner (1976) says "we accept as being "the same"" without considering them under an articulatory, acoustic or perceptual strict category. We have to add that, mother-tongue speakers, even though they do not focus on different tones and pitches, automatically produce

\footnotetext{
${ }^{5}$ Arabic, like English has a stress-timed rhythm.
} 
and understand their mother tongue helped by natural language acquisition; rather foreign students need to be systematically instructed about pronunciation and intonation if we want them to achieve good communicative results. This problem is increased since languages have more than one allophone corresponding to the same symbol (in English, for example, two allophones are representing the same phoneme ' $\mathrm{p}$ ', one is exploded-aspirated with a puff of air following it $\left[\mathrm{p}^{\mathrm{h}}\right]$ as in pin, the other is unexploded as in spin or capture; the $t$ sound in the words hit, tip and little have different allophones because even though phonemically they are considered to be the same sound they are very different phonetically in terms of aspiration, voicing and point of articulation). The problem is difficult to face since different languages have different numbers of phonemes ( $c$ and $b$ in cat and bat are different phonemes) and different allophones to represent them, so it is easy for the students of foreign languages to associate one foreign sound to a similar sound of the mother tongue, thus, pairing the two of them.

"We ignore differences of individual voice quality and of absolute voice pitch as between men, women and children; we certainly notice them and act upon them, but we are able to go beyond the differences to a sameness which is essential to communication as a social activity." (O'Conner 1976, p. 121)

If we start from the general consideration that intonation and prosody are essential features which highlight the speaker's intention, interest, attitude and responsibility about the topic discussed among natives, even more, the concern will be when speakers of different countries meet for communicative purposes. Phonetics, phonology and prosody should be subjects included in the school curriculum even for native speakers, for both students and teachers.

In brief, the course here suggested might go through four steps: 1) to learn how to pronounce the single phoneme, 2) to understand its mechanism, 3) to include it within words, 4) and to give it the right intonation while being aware of the exact position of the mouth, lips and tongue (Figure 3). These steps become essential aids during a foreign language plan because the student should be aware not only of the different intonation patterns related to the foreign language, but also of the exact pronunciation of isolated phonemes, first, and then of these within words and phrases. The care of one's own voice (how to modulate, soften, enrich, etc.) as well as a proper physical exercise of the muscles of the vocal tract, is a valuable practice of great effectiveness because it will highlight the difference between the phonetic and phonological system belonging to the two languages (the mother tongue and the foreign language). To pursue this aim, of course, we need a collegial participation of the teachers of a) the mother tongue, $b$ ) the foreign language, and c) the researchers of the department of Experimental Phonetics handling with care both spectrographs and the laryngographs. 
Figure 3. The Mouth Positions
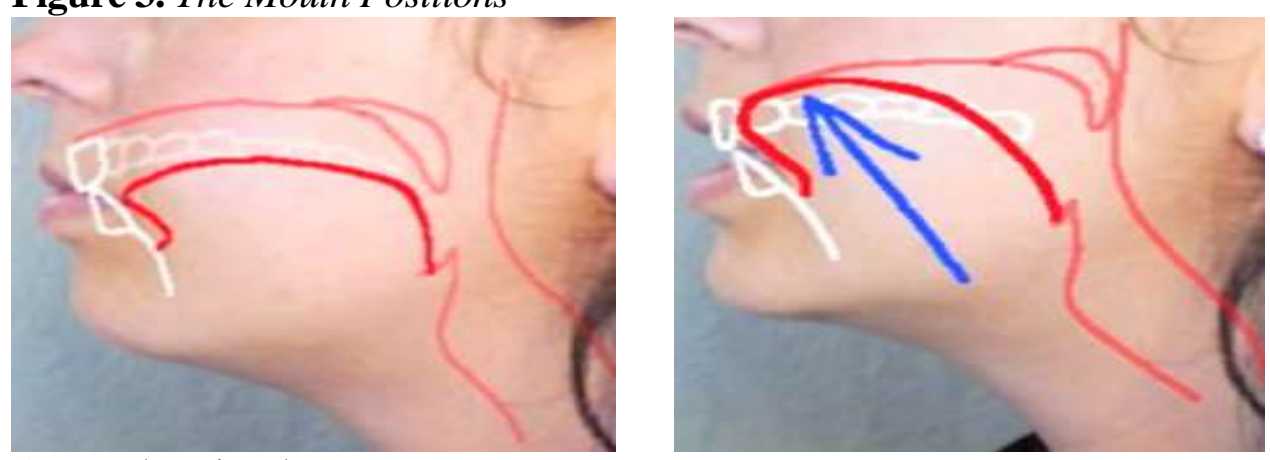

Source: Phonetic Laboratory.

A final consideration should be debated, that is the one related to our global world, which is called multilingual and multiracial, only because there is a huge migration flow of people from their own land to new countries either for improving their standard of life or because forced by miserable conditions in their motherland. Under these circumstances, multilingualism and multiculturalism do not involve the natives, but simply migrants who have to learn the language of the host country just to survive. With so many languages and cultures around us it is simply unacceptable to ignore them and to study only English because its knowledge will offer better working opportunities. Plurilingualism should be the answer for two reasons 1) because it will save many languages from extinction, 2) because it will help migrants to feel less isolated, offering them the occasion to teach their languages, and so the natives may take advantage of mother-tongue speakers, and 3) because it will enrich both the mind and the mother tongue, besides facilitating the learning of English as lingua franca; a language nobody must ignore any longer. It has been proved that the more languages you know the easier their learning will be.

"The last speakers of probably half of the world's languages are alive today. As they grow old and die, their voices will fall silent. Their children and grandchildren - by overwhelming majority - will either choose not to learn or will be deprived of the opportunity to learn the ancestral language. Most of the world's languages have never been written down anywhere or scientifically described. We do not even know what exactly we stand to lose - for science, for humanity, for posterity - when languages die. An immense edifice of human knowledge, painstakingly assembled over millennia by countless minds, is eroding, vanishing into oblivion. ... many linguists now predict that by the end of our current twenty-first century - the year 2101 - only about half of these languages may still be spoken." (Harrison 2007, p. 3)

Then culture, which is a feature strictly linked to language, will help to achieve better cognitions not only for young children but for adults, too, who will gain a more tolerant attitude towards the other, often viewed as an enemy only because s/he is a stranger with different customs and religions (D'Acierno Canonici 2021). 


\section{The Brain}

During the foreign language learning growth, the creative function is central, just because language is a creative process.

"In acquiring a language, a child does not memorize the utterances he hears; rather, he somehow utilizes these utterances to construct for himself a grammar, that is, a collection of rules in accordance with which he can produce and understand an unlimited number of utterances, many of them new to him and not similar in any significant sense to those previously encountered. The rules that constitute the grammar of a particular speaker determine in detail the form of the sentences that the speaker will produce and understand." (Chomsky and Halle 1968, p. 249)

As Chomsky attested, the speaker always creates new sentences, even sentences never heard before, and this happens because of both the structure of the brain and the inborn attitude for learning languages. The brain, in fact, stores all the knowledge received, and, uses that knowledge when it is necessary. Considering foreign languages, the brain, time by time, accumulates the new notions referred to grammar, syntax, vocabulary, intonation, stress, etc., and processes them. It interiorizes them, and when the stimuli arrive, all the previous knowledge is ready for use. During this procedure, the brain does not work in isolation, but collaborates with the ear, the muscles of the vocal area, the lungs, the larynx, the tongue, the lips by sending them the input received and previously stored. It is a complex neurological activity which takes time when learning both the mother and the foreign language, and it relies principally on repetition and memorization of words, phonemes and the whole of the new information related to the foreign language.

Let us explain how the brain is influenced by the exercise of repeating utterances and single phonemes. During the training of phonetic and phonological foreign utterances, students are helped by the brain plasticity, which activates, besides the sensory system, the movement system, too (Figure 4). Control of movements adapts to the changing demands, thanks to neural plasticity. It is a question of reflexes, controlled by neural circuits either in the spinal cord or in the brainstem. Our reflexes can be trained in order to be increased, or even suppressed. In brief, by changing the stimuli of the reflexes (increasing, reducing or suppressing), we might alter body movements, which depend on controlling reflexes according to the signals coming from the motor cortex. It is a circuit caused by of the neural plasticity which strengthens the synapses, which in turn activate the reflexes. 
Figure 4. Body and Brain



Source: Wikipedia.

In conclusion, brain plasticity works in favour of muscle movements (Figure 5). In our case, when viewed under the foreign language learning perspective, it favours the movements of the muscles of the vocal tract, which move into the position required by the linguistic stimuli received. If the stimuli belong to the mother tongue, the signal received is already familiar, and there is no training for the muscles to follow; rather, if the brain receives a new signal, it will send new input to the muscles that have to prepare to provide new movements and new forms of stretching. The neural plasticity adapts the muscles to acquire new shapes in order to emit new sounds. The brain, the reflexes and the muscles reorganize their functions and, because of their flexibility satisfy the new linguistic stimuli.

\section{Figure 5. The Brain}

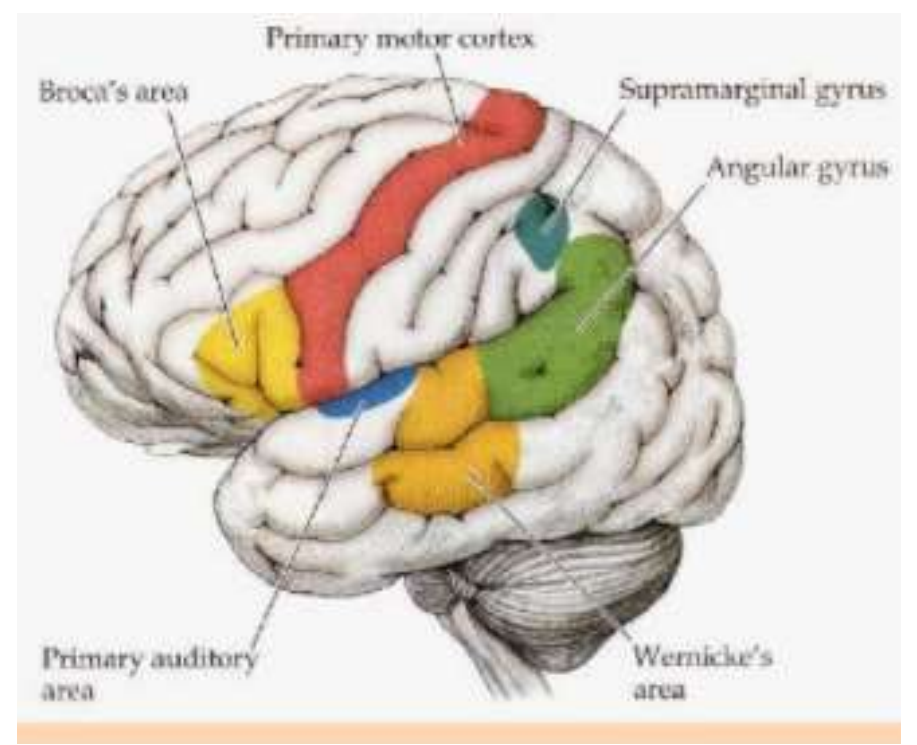

Source: Wikipedia. 
Recent studies have suggested that the only difference between an adult and a child while learning foreign languages is during the acquisition of pronunciation, since the muscle of the vocal tract have not been trained enough for the production of foreign sounds. This skill is so problematic because the muscles have acquired the shape for the emission of sounds belonging to the phonemes and phonology related to the mother tongue. New researches have revealed the incredible neural flexibility of the developing (and aging) brain. Karni et al. (1995) demonstrated expansion of cortical involvement in performance of motor tasks following additional learning in other words, the cortical map can change even in adulthood in response to enriched environmental or learning experiences (Genesee 2000). It is the cerebellum, however, which mainly regulates and coordinates not only movement but posture, balance and motor learning (D'Acierno 2015, cf. Genesee 2000, Karni et al. 1995; Greenenough et al. 1993).

Repetition, oral practice and a lot of patience reformulate the structure of the brain, that of our body as well as that of our behaviour. Of course, as already pointed out, repetition, as experienced by the child, linked to empathy, will guide the student during the whole of the foreign language learning process following the child's steps. The child not only repeats what has heard after the adult aloud, but he continues his exercise by repeating himself. Repetition is a skill that comes after imitation; imitation of the teacher's movements of the lips and the tongue, imitation of his/her intonation after mastering the formal acquisition of the phonetic and phonological 'rules', and after visualizing the voice on the screen of specialized instruments. This brain plasticity never finishes, because the new stimuli generate new synapses which reinvigorate the human brain at any age, even slowing the aging consequences.

"That muscles reflexes can be made more active and easier to elicit by training is another sign of how use can affect the function, which can be explained by neural plasticity being accomplished by training where activation of neural plasticity can make synapses less effective and thereby weakening reflexes. ... learning to speak as a child involves neural plasticity that is activated through training. Later in life, learning to pronounce unfamiliar words requires involvement of neural plasticity for proper activation of the many different muscles that are involved in speech production. Training is necessary for being able to pronounce unfamiliar words, but after some attempts it becomes natural. That means neural circuits have been changed appropriately to produce a new series of commands to muscles. Training of muscles function involved in speaking can make it easy to pronounce such unfamiliar words. The skill remains for a long time, often forever.” (Møller 2009, p. 65)

In essence, every detail belonging to the sound of the foreign language is analysed by the whole body before being able to produce it. If the learner has been sufficiently instructed to recognize the sounds s/he hears, through a well-planned course in phonetics and prosody, his/her ear will be able to recognize all the nuances of the spoken language by sending impulses to the brain, which in turn, sends commands to the lungs, the vocal cord, the tongue, the jaw, the lips. When the student realizes that there is no gap between the written and the oral language, and also, there is no gap between his language and that spoken by a native speaker, 
s/he will enjoy the learning and will proceed with more enthusiasm. On the other hand, if the course has not offered this global view of the language, the written and the spoken skills will remain separate, betraying the real essence of the tongue. For the unfortunate learner the foreign language will remain foreign for ever. Rather, language is a single unit made of both the written and the oral skills, being always creative, but meanwhile, respecting its linguistic system.

\section{Methodology}

The methodology suggested here, in other words an approach stressing the role of phonetics, phonology and prosody, takes its implications from personal studies and researches on bilingualism, plurilingualism, language growth in both children and deaf population, as well as from anthropological studies about how language achieves communication helped by the context in which the message evolves, also helped by the environment from which the speech act matures because of certain types of inputs that stimulate the message (D'Acierno 1990).

The aim is to let students acquire a linguistic competence that will embrace pronunciation, intonation, grammar, syntax, including socio-cultural features, as one of the main means of communication (Hymes 1971). A linguistic competence that will offer the occasion to interact either as listeners/addresser or as hearer/ addressee. I do not mean that students have to be forced to become perfect mothertongue speakers (this will surely demotivate them, since for an adult is very difficult), but they should be stimulated to improve their oral performance as much as possible. Teachers have to plan the course according to the learners' expectations never questioning about their ability.

Since the spoken language is a gift for most people, while the written ability is more limited, I think that emphasis should be, in any case, to improve the 'Verb', the 'Word', the speech, the oral language, which is used more commonly and more often in order to give and receive information of any kind, from a simple request at the greengrocer's to a formal question during a conference. Within these features the voice becomes central.

In conclusion, to convince people that phonetics, phonology and intonation are the pillars of any foreign language planning, and they require a great deal of patience and practice, we have to stress that 1) speech is a highly skilled motor activity, which can be studied as part of the general study of movement, 2) speech is also a type of sound, generating sound waves which can be compared with other types of sounds from the perspective of general acoustics, and 3) falling the language under the category of sound, it is associated with music, so it has to respect certain tones, vibrations, intonation and rhythm in order to represent correctly the notes (phonemes) to be played/spoken. Under these premises, speech becomes an important skill which needs 1) to hear and recognize sounds, 2) to practice them many times, so to facilitate the muscles of the vocal tract to acquire the regular elasticity to produce all the allophones belonging to the language studied, and 3) to achieve an adequate intonation respecting the formal scheme typical of the foreign language. Once these essential features have been mastered, 
the speaker will be able to add also his/her own intonation, so to show his/her attitude toward the topic discussed without altering the content of discourse.

In essence, how we do with gymnastics and music, when we repeat the same physical exercise or we practice the same sheet-music every day for so many times, so we will ask our students to do with the foreign language sound system.

"Language and music define us as human. These traits appear in every society, no matter what other aspects of culture are absent. ... The central role of music and language in human existence and the fact that both involve complex and meaningful sound sequences naturally invite comparison between the two domains. Yet from the standpoint of modern cognitive science, music-language relations have barely begun to be explored. ... Focusing on commonalities over differences claims that these two domains, although having specialized representations (such as pitch intervals in music, and nouns and verbs in language), share a number of basic processing mechanisms, and that the comparative study of music and language provides a powerful way to explore these mechanisms." (Patel 1998, p. 2-4)

The brain, too, works for the three subjects in the same way, because it has to a) memorize and b) recognize the inputs in order to send commands to the physical organs (muscles, ears), to the mind requiring concentration, and to our soul in order to stimulate the right emotions needed to perform each act. In addition to the physical specific organs required for each exercise (legs, or arms in the gym, arms and finger when playing a musical instrument, muscles of the glottis, and cultural body movements when speaking a language), visual aids, too, become essential for any of these activities, since they add motivation coming from the feedback we receive during our communicative or physical or musical performance.

Teaching how to speak a foreign language, in an adult subject, needs 1) to emphasize the exact pronunciation of single phonemes first, 2) to let students visualize the position of the tongue, the lips, and 3) to feel the vibration of the vocal cords helped by images showing the internal position of the organs. Once the learner associates each phoneme to a specific position, the brain memorizes it, and after a series of exercises the brain will automatically send the input to the organs implied. In more abstract terms, learning a new speech sound involves the brain to recognize it and send it to each area deputed to language, so the speech organs adopt a new position, after acquiring a new flexibility; at last, the brain associates this new activity with a new and distinct auditory percept. During this process, students may be led to a new awareness of their own vocal organs, especially if they have never studied any foreign language. By starting with the sound of the alphabet, students and teachers will be helped to face pronunciation more practically. They have a few steps to follow: 1) to listen to the sound; 2) to produce a vocal imitation of it as many times as possible; 3 ) to become aware of the muscles of the glottis implied; 4) to listen to the sound once more, and 5) to reproduce and record it, so to compare the original sound with one's own. During all these steps the visual and vocal organs, as well as the brain, are implied, also involving emotions like motivation, shyness, hesitancy, self-confidence, etc. etc. All these feelings have a heavy weight during the foreign language learning 
process and might even disturb the acquisition of the new tongue. It is the teacher's duty to motivate even adult university students by using all the strategies he/she thinks useful to raise their interest. One device, I have experimented with my learners, is to cover, during the language course, also cultural habits, enriched with anecdotes and personal experiences in the foreign country. In so doing, the lesson becomes less monotonous, while providing cultural details involving the real life of the foreign people; it will also link formal and informal language to habits and behaviour. This happens because language is a vital process, which follows the speakers' life, shaped on, and at the same time shaping the environment and the context it belongs to. The utterances pronounced are not isolated pieces of language, they inevitably match with both content and cultural background.

The acoustic signal defines the common ground between the study of speech production and the study of speech perception. Experimental phonetics includes at least some aspects of both the study of speech production and the study of speech perception.

Stress on phonetics is not a new study, rather it is a new strategy not yet enough appreciated and applied to foreign language teaching. The various nuances of intonation give shape to the spoken communication. During speech, the accent, the rhythm, and the stress we put on some words make plain the significant distinction of meaning more than the grammar and the vocabulary chosen. In addition to the exact intonation, also the pronunciation of single words has to follow established phonetic patterns, otherwise the words not only lose their meaning, but most importantly, mislead the whole message. When the learner has achieved an acceptable level on intonation, s/he can use and also recognize those patterns of pitch that imply a more personal attitude. This evidence is much clearer when the spectrograph let us visualize the different pitches of our voice related to the same sentence, each time meaning differently, according to the event within a specific context: e.g., I thought you were going to the party (but you did not or you did). If the same sentence is included in a written text, it will be the whole essay to offer the exact meaning after a strict analysis of the events described and the general syntactical structure employed. Rather, we cannot hazard any hypothesis about the meaning of an oral speech if we are not able to distinguish the many nuances related to intonation.

Anyway, even though Phonetics is still considered a second-hand branch compared to syntax and grammar, we must appreciate Bloomfield's interest for this area. For him in 1934, language was a string of phonemes: "a sequence of 'strings' of morphemes and ... language would actually consist of such units and it was the task of the linguist to establish what they were and how they related to one another and the other (smaller) units of the language" (Bloomfield 1933, p. 274). His theory was associated with the 'mechanistic' point of view, opposing the mentalists, because he thought that language should be examined in scientific terms. Of course, Palmer, at that time, did not agree with him and to prove his opposition he used, as examples, words like love or hate, which cannot be reduced to a scientific element of analysis like the word salt Bloomfield used to prove his theory. Moreover, Palmer pointed out that also another of Bloomfield's prediction was false. He referred to the fact that also the oral language with its phonemes, sounds 
and the like, could never be defined in purely physical terms in specific laboratories, because at that time they had only an automatic typewriter "that can take dictation and is still a long way from perfection ...there has been no simple machine that will simply convert speech into written symbols" (Palmer 1975, pp. 107-109). We all know now that Bloomfield's prediction was truthful. In fact, the spectrum let us visualize sound waves, tones, pitches, length, stress, etc. providing us with a valuable task when comparing voices, in order to push our motivation to earn a better imitation of mother-tongue speakers. The student achieves a better speech perception when s/he is able to recognize and identify individual phonetic elements as well as the whole intonation and length of a complete utterance. Speech perception is also applied to the study of word recognition, because by visualizing the rhythm of the whole sentence it is easier to isolate and recognize single words. During a speech act, words are strictly linked one another.

\section{Conclusions}

I hope that the almost satisfactory results obtained after the combination of audio and written discourse will surely stimulate the future plans related to the teaching of any foreign language, but in particular of English which has become the only language used all over the world during international meetings. We cannot accept listening to low-level English; it disturbs the whole communicative act, even belonging to very interesting matters, and interrupts important commercial transactions.

Testing pronunciation and intonation was not contemplated in the past. Nowadays, it seems that this area related to foreign languages is gaining space and time, helped by spectrographs that immediately give their answer by making possible a strictly and accurate comparison between the mother-tongue's voice and that of the student, thus, stimulating her/his interest and desire to achieve better results. In so doing, s/he gains an insight into the real problems concerning communicative competence. Achieving communicative competence will mean to satisfy both the teacher and the learner's expectations. On the contrary the language/teaching process will be betrayed:

"... the harm that we do our students by not teaching them a foreign language or by teaching it as if it were just different words from those of our own language lies in the false idea they will hold of what it means to learn a foreign language. They will never be ready to struggle to pronounce things in different sound units, different intonation, different rhythm and stress, different constructions, and even different units of meaning unless they realize that this is exactly what's involved in learning a foreign language, and that although learning those things will require effort, often dull and uninteresting, the rewards for the effort will be great." (Lado 1981, p. 8)

The road is still long and difficult, and courses in phonetics and pronunciation are nowadays more widely spread on the computer through You Tube. We principally rely on students and their motivation to take advantage from the many courses offered by audio-video programs related to phonetics phonology and 
pronunciation, very often also adding phonetic transcription using I.P.A. Even cellular phones, which I use as much as I can, also during the basic English and Arabic lessons offer each student quick evidence of perfect pronunciation. We hope that the above-described technological instruments (spectrographs and laryngographs) will, at last, find their road towards the foreign language teaching/ learning process without remaining limited to improve comprehension within the field of language disorders. I hope this research will support those who really believe that the sound of the voice comes before the written system, and it is the real beginning of everything, as we learn in the sacred texts from the Ancient Hindus to the Old Testament, the Gospel of John and the Holy Qur'ān. In these books the Word, the Word of God guides people for all their life.

John1: 1 In the beginning was the Word, and the Word was with God, and the Word was God.

The ancient Egyptians had Thōth, "the power of the name, and no creature animate or inanimate could be said to have an existence until its name was called. ... In the Ancient Hindu writings, speech is personified as a goddess, Vāk. ... To the Ancient Hindus the world was created by 'verbal being' with 'the world building power' of Vāk. God created the world by saying bhï. ...The speech of man gave him special power in the performance of sacrifices and in the recitation of the mantras or fixed and prescribed language forms .... In the Tântras the meaning of all speech as well as of the mantras is its magical 'power.' A mantra is the living symbol of a deity, and its meaning is its power. In other words, the meaning of God is the power of his Name" (Firth 1937, pp. 4-5).

Indeed, Kun (كُن), Fiat, is the command God gave the universe to be, to exist, and then, the world came into existence: Fayakun (فَئكَن. The sound of this single word pronounced by God had the power to give life to a complex nature, as well as to a more intricate nurture process involving the human being. The association of sound and speech has been established from the beginning, thus, becoming the very first element in the universe. In fact, in Arabic the verb reduces the infinitive form to a noun and calls it masdar (مَصْدَر) which means source, origin, reminding that before the action there is the verb ${ }^{6}$.

To sum up, whatever the origin of the language either divine (early chapters of Genesis - God's gift) or natural, the real problems about its evolution started after Sir William Jones' discovery of Sanskrit in the seventeen-eighties. But the problem related to language evolution had always occupied the human mind. Socrates, while leading a discussion with Plato in the Cratylus, came across words that he supposed to be not of Greek origins rather belonging to barbarian neighbours, whose language was unknown to the Greeks. Rousseau's essay the Origin of Languages (around 1750), in which we read about the relation of language to music, is considered the landmark of the discussion between the old and the new perspectives concerning the origin of language. The imperfection of language held by Herder was the focal point to sustain the natural evolution of

${ }_{6}^{6}$ The noun Kalam (speech كالم) is the science related to God's word (علم الكالم). 
language. Then, Rask, Grimm, Bopp, and Friedrich Schlegel's The Language and Wisdom of the Indians, in which it was faced for the first time a comparative analysis between Sanskrit and some of the European languages (Greek, Latin and German) gave a further push to the theory concerning the natural evolution of language. Max Müller's The Science of Language (1861) aimed at analysing language from a scientific point of view similar to that applied to geology, anatomy, etc. Richard Albert Wilson, in his book The Miraculous Birth of Language, pairs the world evolution to that of language; in brief he claims that when the human mind was able to perceive notion related to time and space, because "conscious reason emerged in man" (Wilson 1949, p. 154). Once these notions were established language acquired its real dimension: "Form," or shape, is the natural expression of space; sound, is the natural and direct expression of time. On the passive side the eye is the receiving organ of the expressions of space, the ear of the expression of time" (Wilson 1949, p. 158). At this point Wilson poses this question: "Which of these two, the space-forms of shape or the timeforms of sound, was to prove the natural raw material of language?" he answers this question by saying that "Oral speech is a more universal medium of communication" because it is more practical, even compared to gesture-speech: "It can be heard in the dark, or on the other side of a wall, or while the person's back is turned; while sign-speech requires light for the eye to see, and can only be received when the eye is turned in that direction and no object intervenes. Sound radiates from the speaker in every direction in a way that gesture-speech does not" (Wilson 1949, p. 159). When analysing the origin of speech, Wilson connects it to the mind and points out that both thinking and sound are connected to time, the first is a time process while the latter a time expression: "thought and oral expression become merely the inward and outward sides of a single timemovement. ... Primitive man everywhere apparently felt the causal connection between the two, and acted on the impulse of his feeling in using sound in his very first steps in language." He proceeds by examining also the connection between thinking and the vocal tract; so close an association lasted for so long that the muscles of the phonetic apparatus shaped in such a way to be able to produce sounds and their variables.

"Even in silent thinking we are conscious of a corresponding movement by the vocal organs when we attend to it, though no audible sound issues from the lips." (Wilson 1949 , p. 162)

When Wilson faces the problem related to the birth of the written language, he focuses on the urgency to link time to space, too, in order to materialize, to give language a shape similar to an object. In so doing while the sound hits the ear people felt the urgency to visualize it so they convert sounds into signs: "by the conventionalization of natural sounds, by transmuting sounds into sound symbols, ... the conventionalized sound symbol into which it is converted may express either time or space. This is what has actually been done in every human language. ... the two sounds have been differentiated so as to express space and time with equal facility. ... This is what constitutes language, and has enabled man to elaborate a complete space-time world of mind which rises above the space-time 
world of nature, and gradually approximates towards a complete mental counterpart of it." (Wilson 1949, p. 167).

\section{Acknowledgments}

Many thanks to the Neurological Department in Northwestern University in Evanston, Illinois USA for showing me some of their researches, and to the colleagues Mario Pettorino and Donatella Locchi at University L'Orientale who gave me the chance to attend the Phonetic laboratory, when I was a researcher at Università L'Orientale in Napoli (Italy).

\section{References}

Abberton E, Fourcin AJ (1975) Visual feedback and the acquisition of intonation. In EH Lenneberg, E Lenneberg (eds.), Foundations of Language Development, volume 2. London: Academic Press New York.

Ashby M, Maidment J (2005) Introducing phonetic science. Cambridge: CUP.

Bloomfield L (1933) Language. New York: Holt, Rinehart \& Winston.

Brown R (1958) Words and things. Glencoe, III.: Free Press.

Chomsky N, Halle M (1968) The sound pattern of English. New York, Evanston, and London: Harper \& Row Publisher.

D'Acierno MR (1990) Three types of bilingualism. In Versione Integrale e da IATEFL News Letter N. 4, April.

D'Acierno MR (2015) The inter-relationships between language, music and movement pattern learning. Athens Journal of Sport 2(1): 17-30.

D'Acierno Canonici MR (2021) The evolution of the idea of God: a socio-anthropological perspective. Rome: Irfan Edition.

De Dominicis A (2002) La voce come bene culturale. (The voice as a cultural asset). Roma: Carocci.

Firth JR (1937) The tongues of men and speech. London: Oxford University Press.

Genesee F (2000) Brain research: implications for second language learning. In ERIC DIGEST, Clearinghouse on Languages and Linguistics. Washington D.C., USA.

Greenenough WT, Black JE, Wallace CS (1993) Experience and brain development. In M Johnson (ed.), Brain Development and Cognition. Oxford: Blackwell.

Gunter R (1972) Intonation and relevance. In D Bollinger (ed.), Intonation. England: Penguin Books.

Hall RA (1972) Elgar and the intonation of British English. In D Bollinger (ed.), Intonation. England: Penguin Books.

Harrison KD (2007) When languages die. Oxford University Press.

Hoff E (2001) Language development. Belmont, CA: Wadsworth/Thomson.

Hughes A, Trudgill P, Watt D (2005) English accents and dialects: an introduction to social and regional varieties of English in the British Isles. 4th Edition. London: Hodder Arnold.

Hymes DH (1971) On communicative competence. Philadelphia: University of Philadelphia Press.

Jacobson R (1968) Child language, aphasia, and phonological universals. The Hague: Mouton. 
Jacobson R, Halle M (1956) Phonemic patterning. In Fundamentals of Language. The Hague: Mouton.

Karni A, Meyer G, Jezzard P, Adams MM, Turner R, Ungerleider LG (1995) Functional MRI evidence for adult motor complex plasticity during motor skill learning. Nature 377(6545): 155-158.

Ladefoged P, Johnson K (2011) A Course in Phonetics. 6th Edition. Stamford, Wadsworth: Cengage Learning Press.

Lado R (1981) Linguistics across cultures. Ann Arbor, USA: The University of Michigan Press.

Locke JL (1983) Phonological acquisition and change. London: Academic Press New York.

Locke JL, Jacobson R, Halle M (1956) Phonemic patterning in fundamentals of language. The Hague: Mouton.

Møller AR (2009) The malleable brain: benefits and harm from plasticity of the brain. New York: Nova Biomedical Books.

O’Conner JD (1976) Phonetics. England: Penguin Books.

Palmer F (1975) Grammar. England: Penguin Books.

Patel AD (1998) Music, language, and the brain. Oxford University Press.

Pike KL (1972) General characteristics of intonation. In D Bollinger (ed.), Intonation. England: Penguin Books.

Py B (1996) Reflection, conceptualisation and exolinguistic interaction: observations on the role of the first language. Language Awareness 5(3-4): 179-187.

Read C (1978) Children's awareness of language with emphasis on sound systems. In A Sinclair, RV Jarvella, WJM Levelt (eds.), The Child's Conception of Language. Berlin: Springer Verlag.

Roach P (1983) English phonetics and phonology. Cambridge University Press.

Schneider E, Burridge K, Kortmann B, Mesthrie R, Upton C (2004) A handbook of varieties of English, volume 1. Berlin: Mouton De Gruyter.

Searle JR (1997) Expression and meaning. U.K.: Cambridge University Press.

Smith F (1975) Spoken and written language. In EH Lenneberg, E Lenneberg (eds.), Foundations of Language Development, volume 2. London: Academic Press New York.

Weir RW (1966) Some questions on the child's learning of phonology. In F Smith, GA Müller (eds.), The Genesis of Language. Cambridge, Mass.: MIT Press.

Wells J (1982) Accents of English, volumes 1-3. Cambridge: CUP.

Wilson RA (1949) The miraculous birth of language. London: J.M. Dent and Sons LTD. 
